\title{
PAPER
}

Check for updates

Cite this: Phys. Chem. Chem. Phys. 2017, 19, 27593

Received 26th July 2017, Accepted 20th September 2017

DOI: 10.1039/c7cp05068b

rsc.li/pccp

\section{Nucleation and growth of lead oxide particles in liquid lead-bismuth eutectic}

\author{
Kristof Gladinez, (D) ab Kris Rosseel, (D) *a Jun Lim, (iD a Alessandro Marino, (D) a \\ Geraldine Heynderickx (iD ${ }^{b}$ and Alexander Aerts (iD ${ }^{a}$
}

\begin{abstract}
Liquid lead-bismuth eutectic (LBE) is an important candidate to become the primary coolant of future, generation IV, nuclear fast reactors and Accelerator Driven System (ADS) concepts. One of the main challenges with the use of LBE as a coolant is to avoid its oxidation which results in solid lead oxide $(\mathrm{PbO})$ precipitation. The chemical equilibria governing $\mathrm{PbO}$ formation are well understood. However, insufficient kinetic information is currently available for the development of LBE-based nuclear technology. Here, we report the results of experiments in which the nucleation, growth and dissolution of $\mathrm{PbO}$ in LBE during temperature cycling are measured by monitoring dissolved oxygen using potentiometric oxygen sensors. The metastable region, above which $\mathrm{PbO}$ nucleation can occur, has been determined under conditions relevant for the operation of LBE cooled nuclear systems and was found to be independent of setup geometry and thus thought to be widely applicable. A kinetic model to describe formation and dissolution of $\mathrm{PbO}$ particles in LBE is proposed, based on Classical Nucleation Theory (CNT) combined with mass transfer limited growth and dissolution. This model can accurately predict the experimentally observed changes in oxygen concentration due to nucleation, growth and dissolution of $\mathrm{PbO}$, using the effective interfacial energy of a $\mathrm{PbO}$ nucleus in LBE as a fitting parameter. The results are invaluable to evaluate the consequences of oxygen ingress in LBE cooled nuclear systems under normal operating and accidental conditions and form the basis for the development of cold trap technology to avoid $\mathrm{PbO}$ formation in the primary reactor circuit.
\end{abstract}

\section{Introduction}

Dealing with high-level long-lived radioactive waste remains one of the most important challenges of nuclear power generation nowadays. Long-term geological disposal of this waste is foreseen, either without (open fuel cycle) or with an additional reprocessing step (partially closed fuel cycle). To reduce the burden on geological disposal, in terms of both waste volume and lifetime, various countries are currently developing nuclear technologies that either produce less waste during energy production (such as the generation IV reactor concepts) or that are dedicated to 'burn' existing waste and thus fully close the fuel cycle. In the latter, the approach is to transmute the minor actinides present in spent nuclear fuel to short-lived products using an Accelerator Driven System (ADS).

In some of the most promising generation IV reactor and ADS concepts, lead or lead-bismuth eutectic (LBE) is foreseen

\footnotetext{
${ }^{a}$ Chemistry and Conditioning Programme, Belgian Nuclear Research Centre, Boeretang 200, B-2400 Mol, Belgium. E-mail: kris.rosseel@sckcen.be

${ }^{b}$ Laboratory for Chemical Technology, Ghent University, Technologiepark 914, B-9052 Gent, Belgium
}

as a primary coolant. For example, international efforts are made with the design of a Lead Fast Reactor (LFR) named ALFRED $^{1}$ in the European Union, an ADS in China (Clear) ${ }^{2}$ and Japan (TEF-T) ${ }^{3}$ and even commercial projects such as SEALER by LeadCold. In Belgium, the MYRRHA ADS under development at the Belgian Nuclear Research Centre (SCK-CEN) ${ }^{4}$ aims at demonstrating the feasibility of the transmutation process on an industrial scale.

Despite the fact that considerable knowledge already exists about the nuclear and physicochemical properties of LBE as well as its thermal hydraulic behavior, ${ }^{5}$ extensive R\&D programs are ongoing in several countries to prove feasibility of the LBE technology in the frame of modern safety standards. It is well-known that accurate control of LBE chemistry is a key challenge for the design of reliable LBE cooled systems. Up to now, most chemistry studies have focused on the prevention of steel corrosion by control of dissolved oxygen. However, chemical processes in the bulk of the LBE that may lead to safety issues have received much less attention. Safe operation of LBE cooled systems requires the control of oxygen concentration levels to mitigate coolant oxidation under normal operating conditions. 
For LBE and lead cooled systems, coolant oxidation is equivalent to the formation of lead oxide $(\mathrm{PbO}) .{ }^{6}$ The equilibrium between dissolved oxygen and $\mathrm{PbO}$ in LBE has been studied by, among others, Kishimoto et al., ${ }^{7}$ Ganesan et al. ${ }^{8}$ and more recently by $\operatorname{Lim}$ et $a .^{9}$ for lower operating temperatures.

Sodium fast reactors rely on cold trap purification systems for reliable operation. ${ }^{10}$ Cold trap filtration can be applied to LBE cooled reactors to prevent the formation of $\mathrm{PbO}$ in the primary circuit. However, such purification systems cannot be designed for LBE cooled systems without knowledge on the $\mathrm{PbO}$ nucleation and growth kinetics.

$\mathrm{PbO}$ nucleation and growth (hereinafter referred to as $\mathrm{PbO}$ formation) in bulk LBE can occur in the case of oxygen inleak during normal operation or accident conditions. To date, the only estimation of the quantity of $\mathrm{PbO}$ formation has been based on the deviation from chemical equilibrium or oxygen solubility. Due to the nature of the precipitation reaction this method is not capable of accurately predicting the amount, location and size distribution of lead oxide particles in LBE. Both the rate of formation and the resultant Particle Size Distribution (PSD) are important parameters to asses the consequence of $\mathrm{PbO}$ formation and to establish a viable, long-term filtering strategy.

The rate of $\mathrm{PbO}$ formation is dependent on the initial amount and PSD of $\mathrm{PbO}$ in the system. The initial nucleation event can be dominated by heterogeneous nucleation on surfaces, by nucleation seeds in the LBE bulk or by homogeneous nucleation in the LBE bulk. The experiments in this paper measure the onset of nucleation under bulk-dominated conditions. The onset of nucleation is commonly referred to as the Ostwald metastable point. ${ }^{11}$ Theory predicts that an excess of oxygen, with respect to the saturation value, is needed to promote the formation of new PbO nuclei. Experiments are carried out to directly measure the metastable limit for $\mathrm{PbO}$ nucleation in LBE. Based on the experimental results, we describe a theoretical model for the nucleation, growth and dissolution of $\mathrm{PbO}$ particles in LBE taking into account the effect of the lead oxide particle size distribution on growth and dissolution. This model provides an improved understanding on the formation mechanism of PbO in LBE cooled systems. It enables overcoming the previous limitations of the equilibrium calculations on the assessment of the effect of $\mathrm{PbO}$ formation on the system. It also opens possibilities for future design of $\mathrm{PbO}$ specific filtration techniques for LBE cooled systems.

\section{Kinetic model for nucleation and growth of $\mathrm{PbO}$ in liquid $\mathrm{LBE}$}

\subsection{PbO nucleation}

The present treatment of formation of solid impurities is based on the 'Classical Nucleation Theory' (CNT). This theory is generally credited to the combined discoveries by Becker, ${ }^{12}$ Volmer ${ }^{13}$ and Zeldovich. ${ }^{14}$ CNT is based on the idea of using a capillary approximation. ${ }^{15}$ This means that CNT describes the rate of nucleation based on the macroscopic properties of the fluid (parent phase) and solid (nucleus).

$$
J=J_{0} \mathrm{e}^{\frac{-\Delta G^{*}}{k_{\mathrm{B}} T}}
$$

with $J$ the rate of nucleation $\dagger$ (in nuclei $\mathrm{m}^{-3} \mathrm{~s}^{-1}$ ). Using this general expression, $J_{0}$ is often denoted as the pre-exponential factor and $\Delta G^{*}$ as the free energy barrier or nucleation barrier. ${ }^{15}$ In the present study the nucleation of oxide particles, $\mathrm{PbO}$, from a liquid metal solution will be described. This means that the following general oxidation reaction is considered:

$$
x \mathrm{M}_{(\mathrm{LBE})}+y \mathrm{O}_{(\mathrm{LBE})} \rightarrow \mathrm{M}_{x} \mathrm{O}_{y(\mathrm{~s})}
$$

Specifically for the case of $\mathrm{PbO}$ formation in liquid LBE:

$$
\mathrm{Pb}_{(\mathrm{LBE})}+\mathrm{O}_{(\mathrm{LBE})} \rightarrow \mathrm{PbO}_{(\mathrm{s})}
$$

The nucleation barrier can be seen as the energy barrier that needs to be surmounted to form a nucleus. Nucleation can only occur if this energy barrier is sufficiently low. This is the case when the driving force for precipitation $I,{ }^{16}$ in $\mathrm{J} \mathrm{mol}^{-1}$, is sufficiently high:

$$
I=R T \ln \left(\frac{a_{\mathrm{M}}^{x} a_{\mathrm{O}}^{y}}{K_{\mathrm{M}_{x} \mathrm{O}_{y}} a_{\mathrm{M}_{x} \mathrm{O}_{y}}}\right)^{\frac{1}{x+y}}=R T \ln \left(\frac{\left(a_{\mathrm{M}_{x} \mathrm{O}_{y}}\right)_{\mathrm{eq}} a_{\mathrm{M}}^{x} a_{\mathrm{O}}^{y}}{\left(a_{\mathrm{M}}^{x}\right)_{\mathrm{eq}}\left(a_{\mathrm{O}}^{y}\right)_{\mathrm{eq}} a_{\mathrm{M}_{x} \mathrm{O}_{y}}}\right)^{\frac{1}{x+y}}
$$

with $R$ the ideal gas constant, $K_{\mathrm{M}_{x} \mathrm{O}_{y}}$ the equilibrium constant for reaction (2) and $a_{k}$ the activity of a specific component $k$. Equilibrium activities are denoted by the subscript 'eq'. The activity of $\mathrm{PbO}$ in $\mathrm{LBE}$ is taken as one to represent a pure solid phase. By assuming that the dissolved oxygen concentrations follow Sievert's law, the activity of oxygen can be calculated using the oxygen concentration $C_{\mathrm{O}}$ and the Sievert constant $K_{\mathrm{s}}$.

$$
a_{\mathrm{o}}=K_{\mathrm{s}} C_{\mathrm{O}}
$$

For $\mathrm{PbO}$ formation, with a constant activity of lead in LBE, the factor in the natural logarithm in eqn (4) can be simplified to the ratio of oxygen concentration $C_{\mathrm{O}}$ and oxygen saturation concentration $C_{\mathrm{O}, \mathrm{s}}$.

$$
I \approx R T \ln \left(\frac{C_{\mathrm{O}}}{C_{\mathrm{O}, \mathrm{s}}}\right)^{1 / 2}=R T \ln S^{1 / 2}
$$

The ratio $C_{\mathrm{O}} / C_{\mathrm{O}, \mathrm{s}}$ will be referred to as the oversaturation $S$.

The standard free energy of formation of a nucleus of radius $r$ is calculated by eqn (7), ${ }^{17}$ as graphically presented in Fig. 1:

$$
\Delta G^{\circ}=4 \pi r^{2} \sigma+\frac{4}{3} \pi r^{3} \Delta G_{\mathrm{v}}
$$

The standard free energy of formation is composed of a surface and volumetric contribution. The surface contribution is defined using the surface tension or interfacial energy $\sigma$ of the parent phase, liquid LBE, in combination with the precipitated phase,

† See Appendix C for a complete list of symbols. 


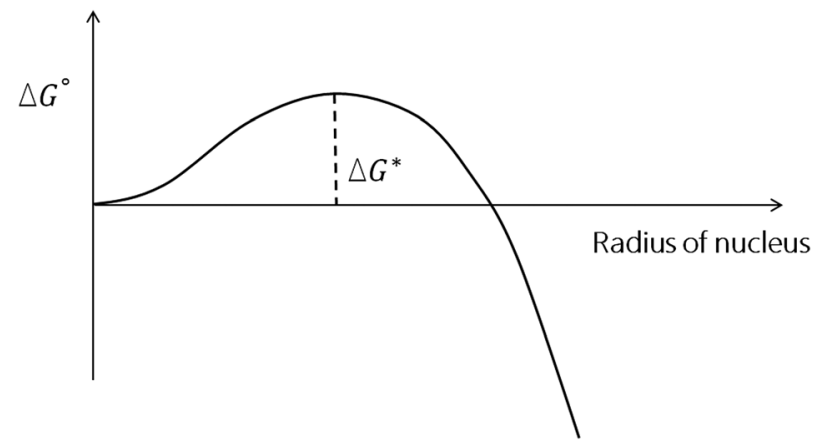

Fig. 1 Free energy of formation $\Delta G^{\circ}$ as a function of the radius of the formed nucleus. The maximum of $\Delta G^{\circ}$ is located at $r=r_{\mathrm{c}}$. The standard free energy of formation is equal to the nucleation barrier $\Delta G^{*}$ for nuclei of radius $r_{\mathrm{c}}$

solid PbO. The volumetric term $\Delta G_{\mathrm{v}}$ quantifies the energy related to the creation of a spherical nucleus per unit volume: ${ }^{18}$

$$
\Delta G_{\mathrm{v}}=-\frac{2 I}{V_{\mathrm{PbO}}}
$$

with $V_{\mathrm{PbO}}$ the molar volume of $\mathrm{PbO}$. The standard free energy of formation (eqn (7)) reaches a maximum at the critical radius $r_{\mathrm{c}}$ and equals the activation energy for nucleation $\Delta G^{*}$ :

$$
\begin{gathered}
\Delta G^{*}=\frac{16 \pi \sigma^{3}}{3 \Delta G_{\mathrm{v}}{ }^{2}} \\
r_{\mathrm{c}}=\frac{-2 \sigma}{\Delta G_{\mathrm{v}}}
\end{gathered}
$$

An assumption is made that nuclei are always formed at the critical radius and that smaller particles are unstable and disappear quasi-instantaneously. The PbO-LBE interfacial energy is required in eqn (7) and (9) for an accurate description of the rate of nucleation as provided by CNT. To the best of the authors' knowledge, direct estimations of the interfacial energy between $\mathrm{PbO}$ and LBE are not presented in the literature. For this reason, the PbO-LBE interfacial energy will be determined based on experimental data (Section 4.1).

The pre-exponential factor $J_{0}$ (eqn (1)) used in CNT can be decomposed into several contributions: ${ }^{17}$

$$
J_{0}=\beta Z N
$$

where $\beta$ is a frequency factor, $Z$ is the Zeldovich factor and $N$ is the number of nucleation sites per unit volume. For homogeneous nucleation, $N$ is often taken as:

$$
N=\frac{N_{\mathrm{A}}}{V_{\mathrm{LBE}}}
$$

with $V_{\mathrm{LBE}}$ the molar volume of LBE in $\mathrm{m}^{3} \mathrm{~mol}^{-1}$ and $N_{\mathrm{A}}$ the Avogadro constant.

The frequency factor $\beta$ is a measure for the number of oxide monomers that can be added to the nucleus per unit time. ${ }^{18}$ A parameter $\Gamma$ is defined, resulting in:

$$
\beta=4 \pi r_{\mathrm{c}}^{2} \sum_{\mathrm{i}} \Gamma_{\mathrm{i}}
$$

where the index $i$ refers to the oxides added to the nucleus. For $\mathrm{PbO}$ nucleation in LBE one can assume that the formed nuclei are only consisting of pure $\mathrm{PbO}$, removing the summation from the formula above. Lehmann et al. ${ }^{18}$ give an overview of different approaches to approximate $\Gamma$. The temperature $T$ (directly and, via the oxygen diffusion coefficient in LBE, indirectly), oxygen concentration $C_{\mathrm{O}}$ and the critical radius $r_{\mathrm{c}}$ (eqn (10)) all have an influence on the value of $\Gamma$.

The Zeldovich factor $Z$ is a measure for the number of oxide monomers needed to change the energy of a critical nucleus by more than $k_{\mathrm{B}} T$, with $k_{\mathrm{B}}$ the Boltzmann constant. It also accounts for the possible decay of critical nuclei to smaller sizes. $^{19}$

$$
Z=\frac{1}{2 \pi r_{\mathrm{c}}^{2}} \frac{V_{\text {oxide }}}{N_{\mathrm{A}}} \sqrt{\frac{\sigma}{k_{\mathrm{B}} T}}
$$

It is important to stress that the effect of the pre-exponential factor $J_{0}$ on the nucleation rate is limited. This factor often has a large value for homogeneous nucleation $\left(\approx 10^{34}-10^{35}\right.$ for the present study) and is rather insensitive to the chosen approximations. The rate of nucleation is thus mainly determined by the exponential part. The full CNT expression leads to a formulation of the rate of PbO nucleation based on the LBE temperature and the oxygen concentration. The nucleation rate is negligible for small values of oversaturation $S$ (eqn (6)) and increases drastically once a given value is reached. This sudden increase in the nucleation rate is a measure to define an empirical Ostwald metastable limit for PbO nucleation. Fig. 2 indicates the trend of the nucleation rate $J$ predicted by CNT at a constant temperature and increasing oversaturation $S$.

\subsection{Growth and dissolution of suspended $\mathrm{PbO}$ particles}

The driving force of particle growth is essentially the same as for nucleation. A difference in dissolved oxygen concentration with respect to the equilibrium or saturation concentration drives the growth or dissolution of a PbO particle in a liquid metal environment. The growth rate can be limited by interfacial kinetics (oxide formation rate) or by mass transfer processes. The present approach assumes that $\mathrm{PbO}$ growth and dissolution is limited by mass transfer and that there is no significant energy barrier to initiate growth. CNT predicts

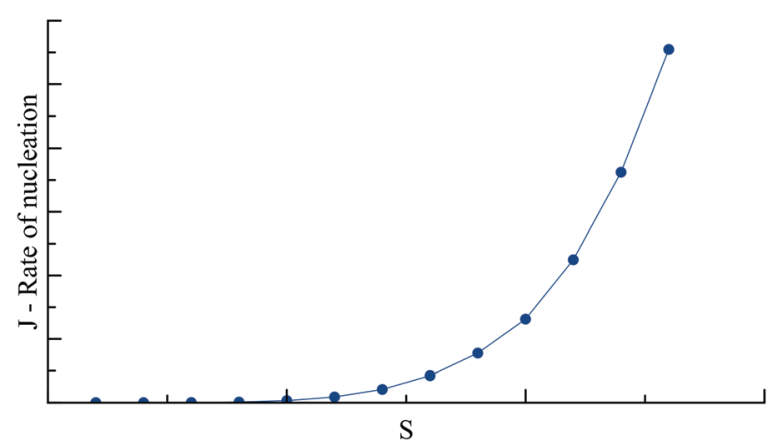

Fig. 2 The rate of nucleation predicted by CNT (for $S>1$ ) at a constant temperature increases sharply with increasing oversaturation $S$. 
very small critical radii in most practical cases (e.g. $\left.10^{-9} \mathrm{~m}\right)$. A mass transfer correlation for suspended particles applicable to these small sizes is chosen. ${ }^{20}$

$$
\mathrm{Sh}=2+0.52 \mathrm{Re}^{0.52} \mathrm{Sc}^{1 / 3}
$$

with the Reynolds number defined as:

$$
\operatorname{Re}=\frac{\rho_{\mathrm{LBE}} \varepsilon d^{4}}{\mu}
$$

with $\mu$ the dynamic viscosity, $\varepsilon$ the turbulent rate of dissipation and $d$ the particle diameter. For small particles, resulting in a low value for the Reynolds number in eqn (15), this can be simplified to $\mathrm{Sh} \approx 2$. This leads to a simple expression for the growth and dissolution of particles.

$$
G_{\mathrm{L}}=\frac{D_{\mathrm{O}}}{r}\left(C_{\mathrm{O}}-C_{\mathrm{O}, \mathrm{s}}\right) \frac{\rho_{\mathrm{LBE}}}{M_{\mathrm{O}}} V_{\mathrm{PbO}}
$$

With $D_{\mathrm{O}}$ the oxygen diffusion coefficient, $r$ the radius of a $\mathrm{PbO}$ particle and $M_{\mathrm{O}}$ the molar mass of atomic oxygen.

\subsection{Kinetic model of lead oxide formation and dissolution}

The full transient behavior of the dissolved oxygen concentration in LBE when subjected to a change in temperature leading to $\mathrm{PbO}$ formation or dissolution can be described as:

$$
\frac{\partial C_{\mathrm{O}}}{\partial t}=J\left(C_{\mathrm{O}}, T\right)+G\left(C_{\mathrm{O}}, T, \mathrm{PSD}\right)
$$

with $J\left(C_{\mathrm{O}}, T\right)$ the change in dissolved oxygen due to nucleation (depending on concentrations and temperature) and $G\left(C_{\mathrm{O}}, T, \mathrm{PSD}\right)$ the change due to growth (depending on concentrations, temperature and $\mathrm{PbO}$ particle size distribution). This equation is discretized in time by means of a numerical implementation of the model in Matlab. The PSD is updated during solution of the equations to account for changes due to nucleation, growth and/or dissolution. Table 1 summarizes the parameters used in the kinetic model.

The PSD is discretized by defining different bins with an average particle radius $r_{i}$ based on eqn (19) as visualized in Fig. 3.

$$
r_{i}=\left(k r_{i-1}^{3}\right)^{1 / 3} \quad i=[1, b]
$$

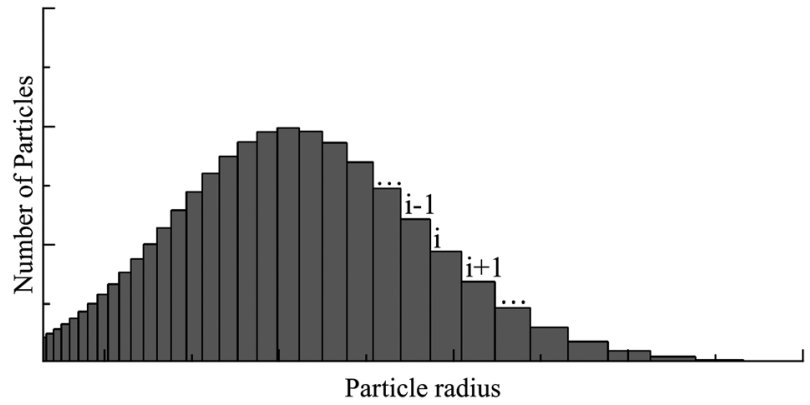

Fig. 3 Example of the PSD discretization based on eqn (19).

with $i$ ranging from 1 to the number of bins $b$. The bin spacing $k$ and number of bins $b$ are chosen such that a sufficiently fine discretization is obtained with a range broad enough to capture the expected size distribution. Consistent results are obtained using a number of bins equal to 200 and a bin spacing equal to 1.2. A lower value of $10^{-9} \mathrm{~m}$ for the particle radius, predicted by using eqn (10), leads to an upper limit of above $10^{-4} \mathrm{~m}$. This is expected to be the largest particle size range allowable by the approximations employed in the definition of eqn (17). The timestep is chosen as 0.1 seconds as this represents a change of less than $1 \times 10^{-3} \mathrm{~K}$ per step. This is thought to be sufficiently small to describe the initial growth of small nuclei with reasonable accuracy.

\section{Experimental}

\subsection{Setups}

The HELIOS3 facility (Fig. 4) is an isothermal setup designed for conditioning batches of $220 \mathrm{~kg}$ of LBE (44.5 wt\% Pb, $55.5 \mathrm{wt} \% \mathrm{Bi}$ ) through gas-liquid interactions at a maximum LBE temperature of $723 \mathrm{~K}$. Conditioning in this context signifies setting the dissolved oxygen concentration in LBE to a desired level. Oxidizing, inert or reducing gas can be added through the cover gas space. The conditioning vessel is equipped with an impeller consisting of 4 Schmidt axially dispersing impellers mounted on a common axis. The impeller is driven by a DC motor connected using magnetic coupling. In the experiments described in this work, the setup is operated between $473 \mathrm{~K}$ and $723 \mathrm{~K}$ at heating and cooling rates of $0.1,0.2$ and $0.5 \mathrm{~K} \mathrm{~min}^{-1}$.

Table 1 Parameters used in the kinetic model of lead oxide formation and dissolution

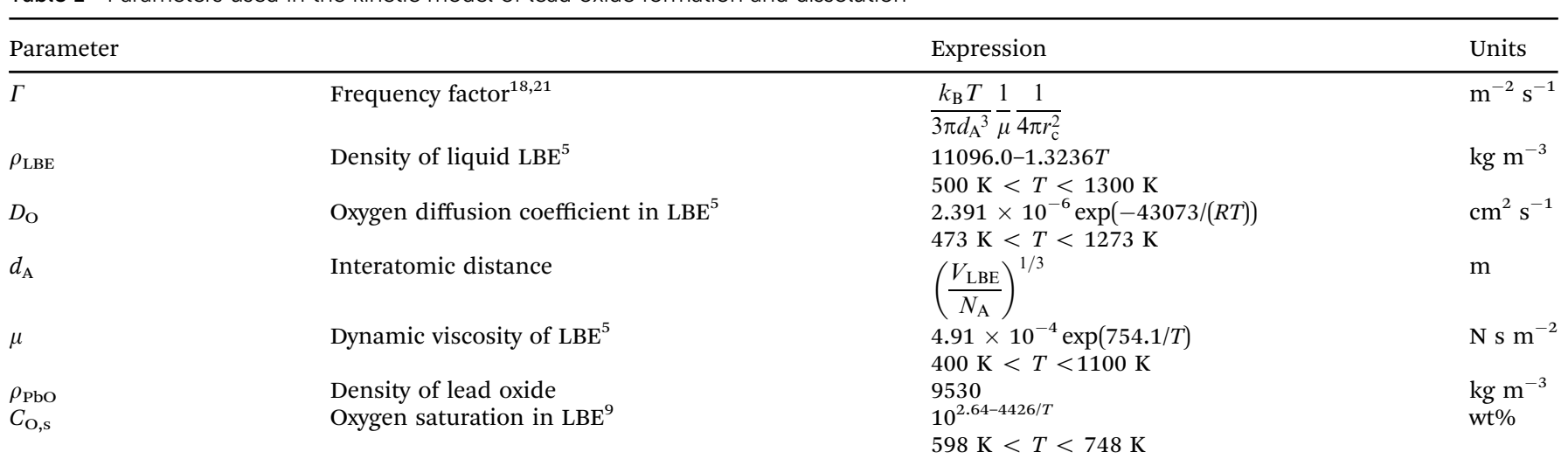




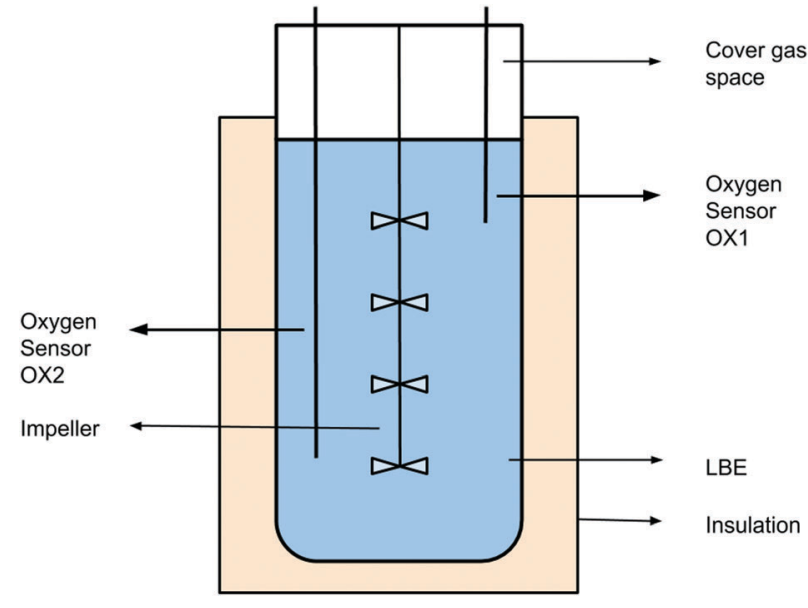

Fig. 4 Overview of the HELIOS3 LBE conditioning setup.

Oxygen concentration in the LBE bulk is controlled by argon (Ar) or argon $+5 \%$ hydrogen $\left(\mathrm{Ar}+\mathrm{H}_{2}\right)$ gas supply to the LBE cover gas space at $723 \mathrm{~K}$. Dissolved oxygen concentrations are measured by potentiometric oxygen sensors with a $\mathrm{Bi} / \mathrm{Bi}_{2} \mathrm{O}_{3}$ reference electrode ${ }^{22}$ (OX1 and OX2) in experiments above $543 \mathrm{~K}$. An additional air/Lanthanum Strontium Manganese oxide (LSM) potentiometric oxygen sensor ${ }^{23}$ is placed in the same circular position as OX2 for measurements below $543 \mathrm{~K}$. For an LBE content of $20 \mathrm{~L}$ the stainless steel surface in contact with the LBE is approx. $0.43 \mathrm{~m}^{2}$ (excluding sensors and the impeller), resulting in a surface-to-volume ratio of approx. $21.5 \mathrm{~m}^{2} \mathrm{~m}^{-3}$. LBE (99.99\%) was obtained from 5N Plus Belgium. The impurities in the LBE are estimated prior to the experimental campaign by means of an inductively coupled plasma mass spectroscopy (ICP-MS) analysis (Appendix A).

The OSCAR facility (Fig. 5) is a small-scale temperaturecontrolled LBE setup with or without a mixer. Three oxygen sensors are installed on the same circular position (two shown). Two Air/LSM and one $\mathrm{Bi} / \mathrm{Bi}_{2} \mathrm{O}_{3}$ potentiometric oxygen senors are used. Oxygen concentration in the LBE is controlled with $\mathrm{Ar}$ (0-100 $\left.\mathrm{mL} \mathrm{min}{ }^{-1}\right)$ or $\mathrm{Ar}+\mathrm{H}_{2}\left(0-110 \mathrm{~mL} \mathrm{~min}{ }^{-1}\right)$ gas supply to the cover gas space. The setup is operated with a small overpressure of 100 to $200 \mathrm{mbar}$. The stainless steel surface in contact with the LBE is approx. $0.07 \mathrm{~m}^{2}$ for an LBE content of $1.8 \mathrm{~L}$, leading to a surface-to-volume ratio of approx. $37.14 \mathrm{~m}^{2} \mathrm{~m}^{-3}$. The temperature ranges used are identical to those in the HELIOS3 facility, with cooling rates of $0.1,0.2$ and $0.5 \mathrm{~K} \mathrm{~min}^{-1}$.

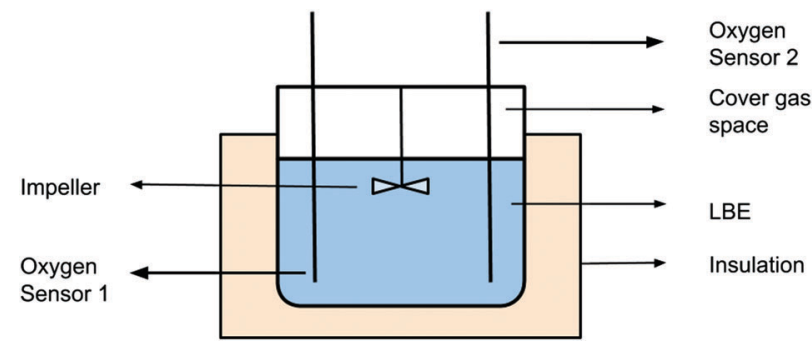

Fig. 5 OSCAR schematic representation.

\subsection{Methods}

3.2.1 Onset of PbO nucleation. A first set of experiments is conducted in both setups to measure the Ostwald metastable limit for $\mathrm{PbO}$ formation in LBE. To determine the onset of nucleation stagnant LBE is cooled at a constant rate. As the oxygen saturation level in LBE decreases with decreasing temperature, the dissolved oxygen concentration in the LBE surpasses the saturation value at some temperature. A decrease in the measured dissolved oxygen concentration indicates the formation of PbO. A decrease of $2 \%$ from the average oxygen concentration at saturation is chosen as a representative criterion to indicate the start of $\mathrm{PbO}$ formation. Cover gas conditions are chosen such that a stable oxygen concentration is obtained in a temperature range of minimal $20 \mathrm{~K}$ prior to the onset of nucleation. This is done by adding small flow rates of $\mathrm{Ar}+\mathrm{H}_{2}$ to the cover gas space to compensate for oxygen inleak. The experiments conducted under inert (Ar) and reducing $\left(\mathrm{Ar}+\mathrm{H}_{2}\right)$ cover gas atmospheres result in comparable values as below $673 \mathrm{~K}$ the kinetics of oxygen reduction by $\mathrm{Ar}+\mathrm{H}_{2}$ are believed to be very slow.

Experiments are conducted with initial dissolved oxygen concentrations in between $10^{-4} \mathrm{wt} \%$ and $10^{-6} \mathrm{wt} \%$ (measured at $723 \mathrm{~K}$ ). A decrease of dissolved oxygen concentration in the LBE bulk is obtained by flowing $\mathrm{Ar}+\mathrm{H}_{2}$ in the cover gas space at $100 \mathrm{~mL} \mathrm{~min}^{-1}$ for OSCAR and $75 \mathrm{~L} \mathrm{~h}^{-1}$ for HELIOS3 at $723 \mathrm{~K}$. Oxygen concentrations are increased by allowing oxygen to enter the system.

3.2.2 Model validation. A second set of experiments is performed in well-stirred LBE in the HELIOS3 facility to validate the proposed theoretical model of $\mathrm{PbO}$ formation. Temperature is changed from $723 \mathrm{~K}$ to $563 \mathrm{~K}$ and back to $723 \mathrm{~K}$ for three cycles. All cycles are performed at $0.2 \mathrm{~K} \mathrm{~min}^{-1}$. In these experiments only Ar supply to the cover gas space is used as a constant oxygen concentration over the full cycle needs to be obtained. Dissolved oxygen concentrations at $723 \mathrm{~K}$ are chosen such that measurement of $\mathrm{PbO}$ formation and dissolution by both the Air/LSM and $\mathrm{Bi} / \mathrm{Bi}_{2} \mathrm{O}_{3}$ potentiometric oxygen senors is possible. The measured dissolved oxygen concentration trends will be compared with the predictions by the kinetic model for PbO formation and dissolution.

\section{Results and discussion}

\subsection{Experimental results in stagnant LBE}

As described in Section 3.2.1, the onset of PbO nucleation is measured in the OSCAR and HELIOS3 setups under various conditions. For example 1 in Fig. 6, the electric potential difference is measured during a temperature decrease in stagnant LBE in the HELIOS3 facility (Fig. 4) by a potentiometric oxygen sensor with a $\mathrm{Bi} / \mathrm{Bi}_{2} \mathrm{O}_{3}$ reference electrode. During the experiment the temperature decreases from $723 \mathrm{~K}$ to $563 \mathrm{~K}$ at a constant rate of $0.1 \mathrm{~K} \mathrm{~min}^{-1}$. The initial oxygen concentration is approx. $7.61 \times$ $10^{-6} \mathrm{wt} \%$. The experiment is conducted with an Ar gas flow of $10 \mathrm{~L} \mathrm{~h}^{-1}$ to the cover gas space. Fig. 6 represents the experimental results with the change in oxygen concentration as a function of 


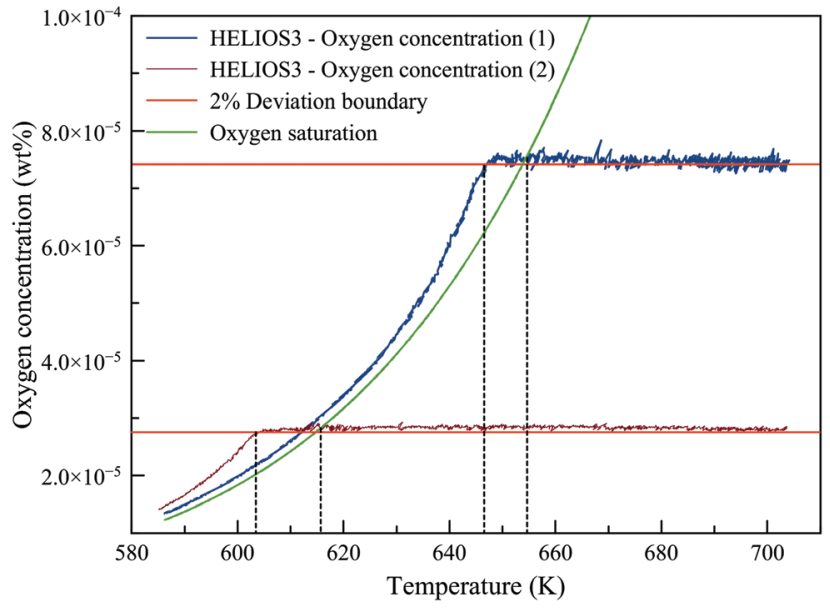

Fig. 6 Measured oxygen concentration by the $\mathrm{Bi} / \mathrm{Bi}_{2} \mathrm{O}_{3}$ oxygen sensor (OX2) in the HELIOS3 setup during a temperature decrease of $0.1 \mathrm{~K} \mathrm{~min}^{-1}$ in stagnant LBE. (1) $C_{O}=7.48 \times 10^{-5} w t \%$; (2) $C_{O}=2.84 \times 10^{-5} w t \%$.

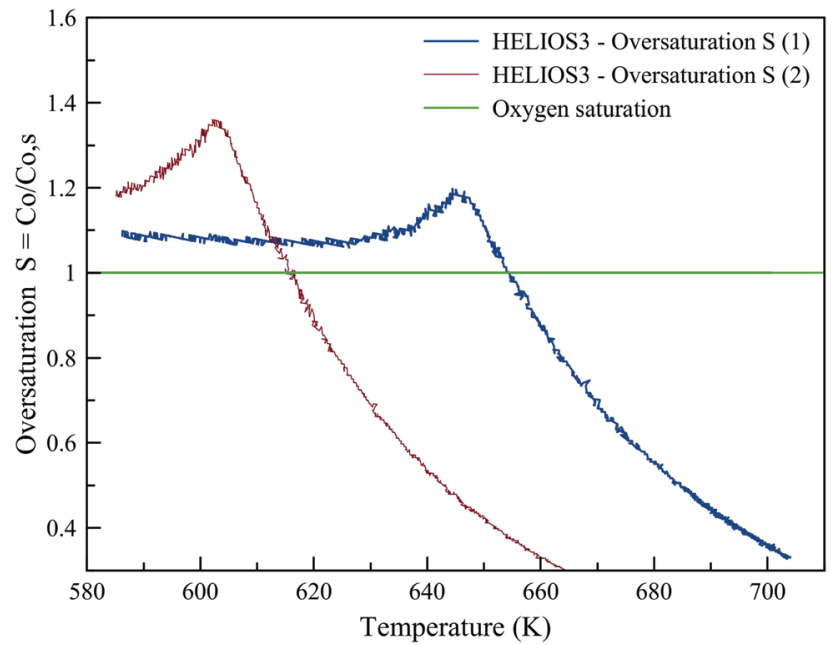

Fig. 7 Oversaturation as a function of temperature in the HELIOS3 setup during a temperature decrease of $0.1 \mathrm{~K} \mathrm{~min}^{-1}$ in stagnant LBE. (1) $C_{O}=$ $7.48 \times 10^{-5} w t \%$; (2) $C_{O}=2.84 \times 10^{-5} w t \%$.

temperature. The dissolved oxygen concentration surpasses the oxygen saturation concentration at approx. $655 \mathrm{~K}$. The point indicating the onset of nucleation is chosen as the intersection of the $2 \%$ line and the measured dissolved oxygen concentration at approx. $647 \mathrm{~K}$.

This result can also be represented with the oxygen concentration relative to the oxygen saturation concentration. This is visualized in Fig. 7 with the oversaturation as a function of temperature. The maximum oversaturation value roughly corresponds to the point selected as the onset of nucleation. However, the maximum is not chosen as the onset of nucleation as it is not sharply defined at all temperatures, resulting in a larger uncertainty on the start of nucleation temperature. Example 2 in Fig. 6 and 7 is measured at a lower oxygen concentration, indicating that a lower initial oxygen concentration results in a larger value of oversaturation.

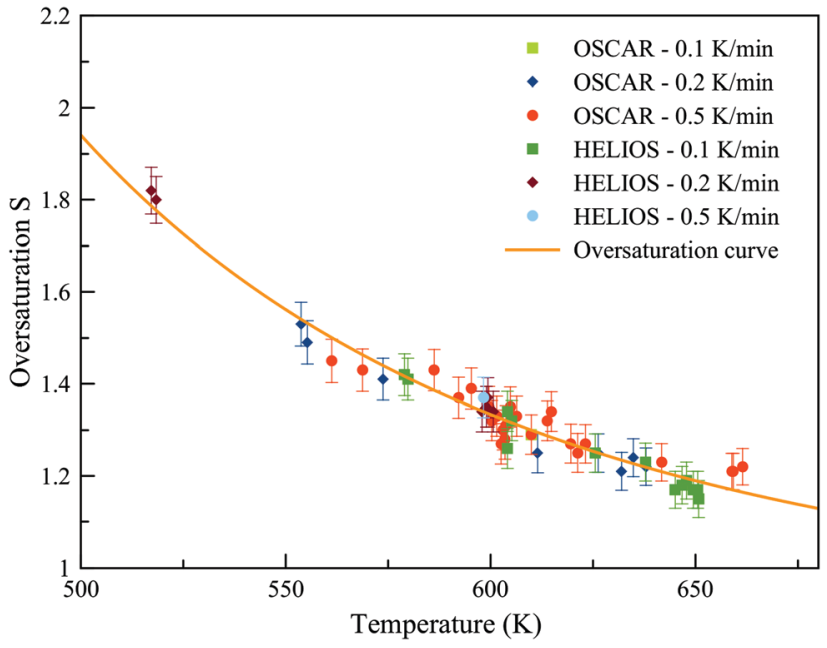

Fig. 8 Overview of the oversaturation measured at the onset of $\mathrm{PbO}$ nucleation. Data obtained in OSCAR and HELIOS3 at cooling rates of $0.1,0.2$ and $0.5 \mathrm{~K} \mathrm{~min}^{-1}$.

Analogous to the previous experiments described in Fig. 6 and 7 , the onset of $\mathrm{PbO}$ nucleation is measured in a broad temperature range. Fig. 8 presents the overview of data obtained from more than fifty cooling cycles in stagnant LBE at cooling rates of $0.1,0.2$ and $0.5 \mathrm{~K} \mathrm{~min}^{-1}$ in both OSCAR and HELIOS3 experimental facilities. Data are obtained down to approx. $517 \mathrm{~K}$. The onset of nucleation, defined by a $2 \%$ deviation of the oxygen concentration from the average value at saturation, is chosen as the reference value for the determination of the effective interfacial energy. Therefore, only concentrations constant within $2 \%$ of the average over more than $20 \mathrm{~K}$ before the onset of $\mathrm{PbO}$ formation are retained for analysis. At temperatures below $517 \mathrm{~K}$ however, this criterion is too strict to allow a correct selection of the point of onset. The results presented in Fig. 8 indicate the temperature dependence of the oversaturation necessary for $\mathrm{PbO}$ nucleation. Values of oversaturation up to $80 \%(S=1.8)$ are observed at $517 \mathrm{~K}$. The uncertainty on the measurement, represented with error bars in Fig. 8, is defined as in Appendix 8.

The onset of nucleation as determined from experiments is matched with the onset of nucleation predicted by the model described in Section 2.3. This is done by using a nucleation rate $J$ of 1 nucleus $\mathrm{m}^{-3} \mathrm{~s}^{-1}$ as the criterion for the onset of nucleation.

$$
J=J_{0} \mathrm{e}^{\frac{-\Delta G^{*}}{k_{\mathrm{B}} T}}=1\left[\text { nucleus } \mathrm{m}^{-3} \mathrm{~s}^{-1}\right]
$$

Using a general expression for the interfacial energy of $\sigma=A+B T$, the definition of $\Delta G^{*}$ from eqn (9) and a constant pre-exponential factor $J_{0}$, eqn (20) can be rewritten as:

$$
S=\exp \left(\sqrt{\frac{-16 \pi(A+B T)^{3} V_{\mathrm{PbO}}^{2}}{3 R^{2} T^{3} \ln \left(J / J_{0}\right) k_{\mathrm{B}}}}\right)
$$

$J_{0}$ is approximated as $1 \times 10^{35}$ using the expressions presented in Table 1 at $600 \mathrm{~K}$. A non-linear least-squares curve 
fitting algorithm is used to determine the most suitable values for $A$ and $B$ with respect to the experimental data. Using the data from Fig. 8 this finally results in the following expression for the effective interfacial energy.

$$
\sigma_{\text {eff,LBE-PbO }}=0.1976-2.4075 \times 10^{-4} T
$$

This value is an effective interfacial energy as it incorporates the uncertainties on the nucleation rate described by CNT in eqn (1). Different parameters chosen for e.g. the preexponential factor $J_{0}$ will lead to a slightly different value for

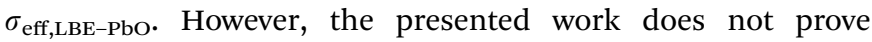
that the observed phenomenon is homogeneous nucleation. Heterogeneous nucleation in LBE is considered possible because of the relatively large number of impurity particles present in the LBE under the conditions tested. Solid oxides, such as magnetite, ${ }^{24}$ can be present in LBE in contact with stainless steel surfaces. The results presented here show comparable values of oversaturation independent of the LBE residence time in the experimental setups, suggesting the absence of dependency on corrosion product impurity content.

The fitting of the kinetic model to the stagnant experiments, using an effective interfacial energy, circumvents the absence of detailed knowledge on the nucleation path for PbO in LBE. From the presented results, it is shown that the observed nucleation is independent of the surface-to-volume ratio and LBE impurity content. This is believed to be sufficient to prove that the observed energy barrier for nucleation is widely applicable. To improve the description of the rate of nucleation in the case of heterogeneous bulk nucleation, the pre-exponential $J_{0}$ factor used in the calculations should be adapted to represent the true number of nucleation sites. As in practice this is not feasible, the present estimation is expected to be sufficient. Using this insight, the effective interfacial energy can be linked to the real interfacial energy of the LBE-PbO system by defining a (unknown) correction factor ' $h$ ' for heterogeneous nucleation as shown in eqn (23).

$$
\sigma_{\text {eff,LBE-PbO }}=h \sigma_{\text {LBE-PbO }}
$$

This correction is equivalent to the definition of a geometrical correction factor (the so-called Fletcher factor ${ }^{25}$ ) on the nucleation barrier (eqn (9)) as described by Kalikmanov. ${ }^{15}$

The metastable limit from eqn (21) can be written explicitly as:

$$
S_{\mathrm{PbO}-\mathrm{LBE}} \approx \exp \left(\sqrt{\frac{33 \pi V_{\mathrm{PbO}}^{2} \sigma_{\mathrm{eff}, \mathrm{LBE}-\mathrm{PbO}^{3}}}{500 R^{2} T^{3} k_{\mathrm{B}}}}\right)
$$

for $515 \mathrm{~K}<T<675 \mathrm{~K}$. The experimental data are very consistent with approx. 95\% of the observed data points in the range of $S \pm 0.05$. In practice, this implies an accurate prediction of the onset of nucleation within $\pm 5 \%$ of the estimated value. The results in Fig. 8 indicate that the onset of nucleation is most probably independent of the cooling rate in the present study. This can be explained by the fast increase of the nucleation rate with the oversaturation, as discussed in Fig. 2. Given the small quantities of oxygen and low cooling rates in these experiments no large oversaturations can be reached. The observed onset of nucleation is

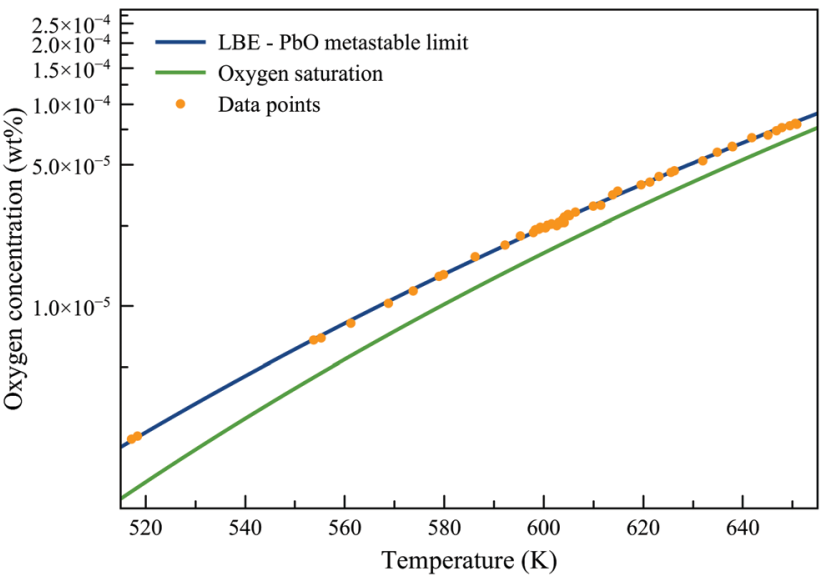

Fig. 9 Ostwald metastable limit for $\mathrm{PbO}$ formation in LBE (indicated in blue) based on experimental measurements in stagnant LBE. Oxygen saturation from Lim et al. ${ }^{9}$ indicated in green.

believed to be related to bulk nucleation. This is confirmed by the absence of dependencies of the onset of nucleation on the cooling rate (as discussed), mixing (discussed in the next part) and surfaceto-volume ratio.

Fig. 9 shows the Ostwald metastable limit for PbO formation in LBE obtained by multiplying the oxygen saturation concentration with $S$ (eqn (21)). At concentrations below the oxygen saturation boundary (indicated in green) only $\mathrm{PbO}$ dissolution is possible. In-between the metastable limit (indicated in blue) and the saturation boundary $\mathrm{PbO}$ crystals can grow but no nucleation of new PbO crystals is observed within the timescale of the experiments. Above the metastable limit (indicated in blue) $\mathrm{PbO}$ nuclei will form. Growth of newly formed nuclei and already growing crystals will occur simultaneously in this region.

\subsection{Model validation}

The theoretical model of $\mathrm{PbO}$ nucleation, growth and dissolution is validated in the HELIOS3 facility (Fig. 4) in stirred LBE. At a constant dissolved oxygen concentration the temperature is cycled at a fixed rate. The impeller rotational speed is found not to impact the results as similar curves (not shown) are obtained by operating at 120 and $240 \mathrm{rpm}$. Therefore, to obtain a homogeneous temperature, oxygen and $\mathrm{PbO}$ particle distribution in the complete setup, the impeller is operated at $120 \mathrm{rpm}$ in all experiments. The transient dissolved oxygen concentrations are shown in Fig. 10.

Fig. 11 shows the results relative to the oxygen saturation concentration. The oversaturation curves obtained by the kinetic model (Section 2.3) describe correctly the initial peak, but tend to overestimate its height in some cases. A fast decrease in oversaturation, almost entirely due to growth of the formed nuclei, is predicted by the model. Experimental results show a slower decrease, especially at lower temperatures.

The measured maximum oversaturation reached in Fig. 11 for cycle 3 does not fully agree with the value predicted by the kinetic model. This difference can also be seen in Fig. 10 where 


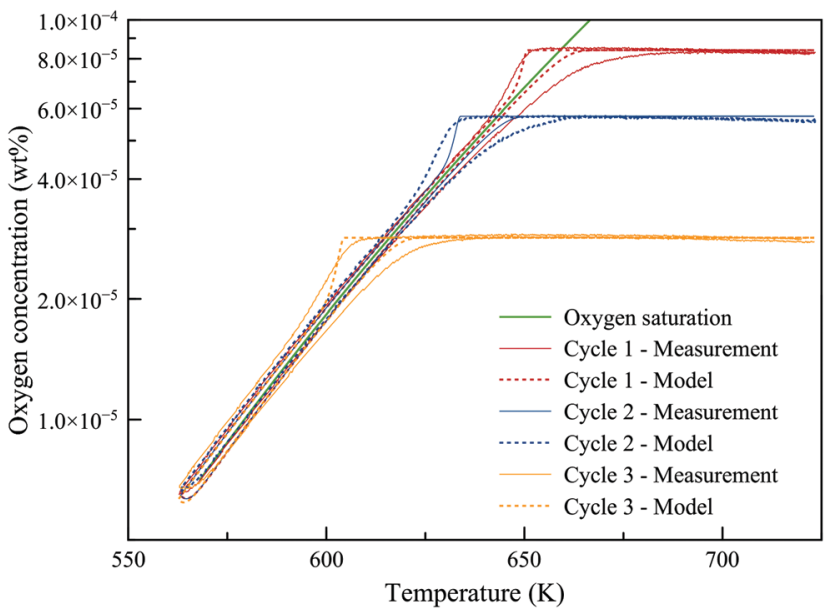

Fig. 10 Dissolved oxygen concentration measured during temperature cycles starting at $723 \mathrm{~K}$ in the experimental HELIOS3 facility. The impeller is operated at $120 \mathrm{rpm}$ and a flowrate of $10 \mathrm{~L} \mathrm{~h}^{-1}$ argon is used. The oxygen concentration curves predicted by the kinetic model are represented by dotted lines.

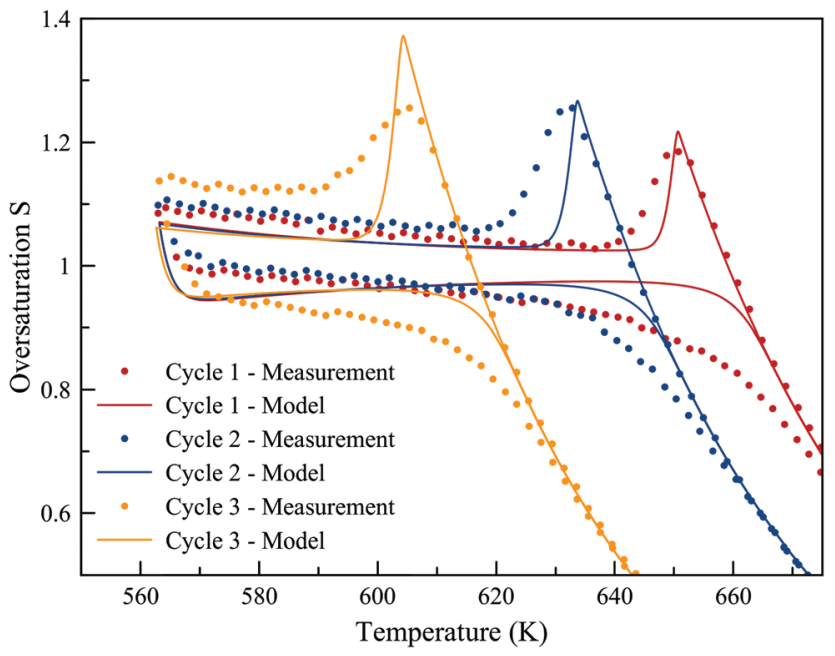

Fig. 11 Oversaturation measured during temperature cycling at $0.2 \mathrm{~K} \mathrm{~min}^{-1}$ in the HELIOS3 facility. The impeller is operated at $120 \mathrm{rpm}$. Cycle 1: $C_{O}=8.40 \times 10^{-5} \mathrm{wt} \%, 723-563 \mathrm{~K}$. Cycle 2: $C_{\mathrm{O}}=5.75 \times 10^{-5} \mathrm{wt} \%$, 723-563 K. Cycle 3: $C_{\mathrm{O}}=2.88 \times 10^{-} 5 \mathrm{wt} \%, 723-563 \mathrm{~K}$.

the experimental values show a smooth onset of $\mathrm{PbO}$ formation whereas the model changes slope more abruptly. The fitting procedure, chosen previously, impacts this overshoot. Another possible explanation is the presence of cold spots in the setup during the experiment leading to localized nucleation. After the initial nucleation event, the model predicts a faster $\mathrm{PbO}$ growth rate than that observed from the experiment. This effect can be attributed to the mass transfer limited growth of the nanometer-scale nuclei. The real $\mathrm{PbO}$ crystal growth at these small scales is most likely limited by interfacial kinetics, leading to a slower change in oxygen concentration. After a certain time, when particles reach larger sizes, the growth rate predicted by the model matches fairly well with the experimental values of oxygen concentration. A second effect limiting

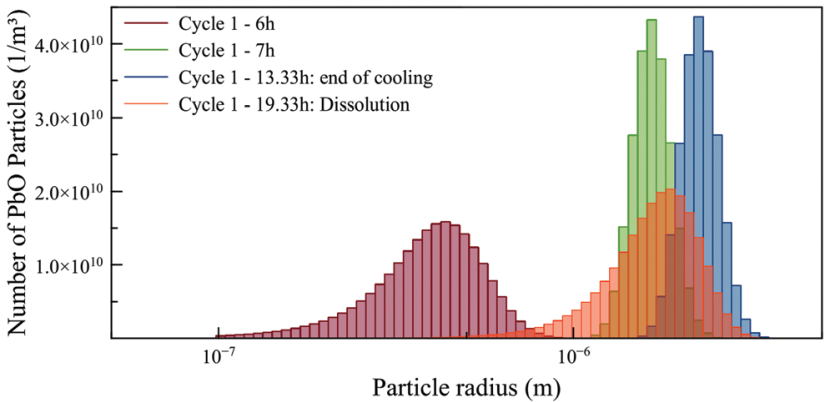

Fig. 12 Particle size distribution of validation cycle 1 predicted by the theoretical model of $\mathrm{PbO}$ nucleation and growth.

the real particle growth rate is particle aggregation. Small particles can collide and form larger aggregates. This process will slow down the observed growth rate and is not taken into account in the present model.

The combination of particle nucleation, growth and dissolution allows the model to track the particle size distribution (PSD) of the $\mathrm{PbO}$ particles during a temperature cycle. This evolution of the PSD is represented in Fig. 12 for cycle 1. Results are shown right after the nucleation event at $t=6 \mathrm{~h}$ and also at $t=7$ and $13.3 \mathrm{~h}$ (end of cooling cycle). After the first, very fast, initial growth of the particles the distribution evolves more slowly. After $7 \mathrm{~h}$ the distribution remains almost constant as the added oxygen becomes negligible at low temperatures. When not considering aggregation, most particles hardly reach the micrometer range. For cycles starting with a lower initial oxygen concentration the resultant PSD predicted by the kinetic model will contain even smaller particles (not shown). This consideration shows that efficient removal of PbO from LBE by standard mechanical filtration is a difficult task. The PSD during dissolution is shown at $t=19.33 \mathrm{~h}$, representing a leftskewed distribution. This is a direct result of the faster dissolution of smaller particle sizes predicted by the proposed mass transfer limited kinetics of growth and dissolution in eqn (17).

Generally speaking a good agreement between the kinetic model of $\mathrm{PbO}$ formation and dissolution and the experimental results is obtained. It should be noted that the proposed kinetic model, based on the parameters for homogeneous nucleation, captures very well the observed transients in oxygen concentration. One possible reason for this qualitative, nearly quantitative agreement is that, within the experiments considered in this paper, no large oversaturations are reached. Using the description of eqn (6) and (10), this means that the critical radius of nucleated $\mathrm{PbO}$ particles is always larger than $10^{-9} \mathrm{~m}$. Such nuclei consist of more than hundred $\mathrm{PbO}$ molecules and can therefore be thought to agree rather well with the macroscopic description provided by CNT.

\section{Conclusion}

Repeated cooling experiments in stagnant LBE are able to identify an empirical Ostwald metastable limit for $\mathrm{PbO}$ formation in liquid LBE. Due to an observed absence of dependency on the 
surface-to-volume ratio of the experimental setup, the measured limit is believed to be widely applicable. Measurements are performed in a broad temperature range, making the results directly applicable to the formation of $\mathrm{PbO}$ in $\mathrm{LBE}$ fast reactors. The experimental results indicate that $\mathrm{PbO}$ formation in $\mathrm{LBE}$ systems is mainly dominated by bulk nucleation. A point-kinetic model of lead oxide formation in LBE is presented. It captures very well the oxygen concentrations under transient conditions. Particle Size Distributions are predicted for homogeneously mixed conditions. Future work would focus on microscopic investigations to take into account the observed particle shape and to validate PSDs predicted by the model. Experiments in loop-type LBE systems with larger thermal gradients are also expected to provide valuable information for further model validation. The obtained results open the possibility of designing cold trap filtration systems for LBE cooled reactors, contributing to an improved control of coolant quality and reliability for future sustainable energy production.

\section{Conflicts of interest}

There are no conflicts to declare.

\section{Appendix}

\section{A Impurity analysis}

Table 2.

\section{B Assesment of the experimental uncertainty}

The sensitivity of the results on the temperature measurements can easily be analytically expressed (example for a $\mathrm{Bi} / \mathrm{Bi}_{2} \mathrm{O}_{3}$ sensor). ${ }^{9,22}$

$$
\begin{aligned}
S= & \frac{C_{\mathrm{O}}}{C_{\mathrm{O}, \mathrm{s}}}=\frac{\exp (4.95-(7104+23209 E) / T)}{10^{2.64-4426 / T}} \\
\frac{\partial S}{\partial T}= & (7104+23209 E-4426 \ln (10)) \\
& \times \exp \left(4.95-\frac{7104+23209 E}{T}\right)\left(T^{2} 10^{2.64-4426 / T}\right)^{-1}
\end{aligned}
$$

eqn (26) can be evaluated at the oxygen saturation electric potential to obtain a representative value of the temperature sensitivity.

\begin{tabular}{lll}
\hline Table 2 & ICP-MS impurity analysis of the LBE sample \\
\hline Element & & Content \\
\hline $\mathrm{Pb}$ & $\left(\mathrm{mg} \mathrm{g}^{-1}\right)$ & $470 \pm 50$ \\
$\mathrm{Bi}$ & $\left(\mathrm{mg} \mathrm{g}^{-1}\right)$ & $600 \pm 60$ \\
$\mathrm{Fe}$ & $\left(\mu \mathrm{g}^{-1}\right)$ & $<0.4$ \\
$\mathrm{Ni}$ & $\left(\mu \mathrm{g} \mathrm{g}^{-1}\right)$ & $3.34 \pm 0.33$ \\
$\mathrm{Cr}$ & $\left(\mu \mathrm{g}^{-1}\right)$ & $<0.2$ \\
$\mathrm{Mn}$ & $\left(\mu \mathrm{g} \mathrm{g}^{-1}\right)$ & $<0.1$ \\
$\mathrm{Co}$ & $\left(\mu \mathrm{g} \mathrm{g}^{-1}\right)$ & $<0.04$ \\
$\mathrm{Cu}$ & $\left(\mu \mathrm{g} \mathrm{g}^{-1}\right)$ & $27.3 \pm 2.7$ \\
$\mathrm{Ag}$ & $\left(\mu \mathrm{g} \mathrm{g}^{-1}\right)$ & $22.9 \pm 2.3$ \\
$\mathrm{Cd}$ & $\left(\mu \mathrm{g} \mathrm{g}^{-1}\right)$ & $1.08 \pm 0.11$ \\
$\mathrm{Tl}$ & $\left(\mu \mathrm{g} \mathrm{g}^{-1}\right)$ & $5.3 \pm 0.5$
\end{tabular}

The sensitivity of the measurements on the electric potential can be expressed based on the potential difference using the well-known Nernst equation.

$$
\begin{aligned}
E_{\mathrm{O}}-E_{\mathrm{O}, s} & =\Delta E=\frac{R T}{2 F} \ln \left(\frac{a_{\mathrm{o}, \text { ref }}}{K_{\mathrm{s}} C_{\mathrm{O}}}\right)-\frac{R T}{2 F} \ln \left(\frac{a_{\mathrm{o}, \text { ref }}}{K_{\mathrm{s}} C_{\mathrm{O}, \mathrm{s}}}\right) \\
& =\frac{R T}{2 F} \ln \left(\frac{C_{\mathrm{O}}}{C_{\mathrm{O}, s}}\right)
\end{aligned}
$$

with $E_{\mathrm{O}}$ the potential measured by the sensor, $E_{\mathrm{O}, \mathrm{s}}$ the potential under oxygen saturated conditions and $F$ the Faraday constant. The Sievert constant $K_{\mathrm{s}}$ drops out of the equation leading to a simplified expression of $S$ as a function of the potential difference.

$$
\begin{gathered}
S=\exp \left(\frac{2 F \Delta E}{R T}\right) \\
\frac{\partial S}{\partial \Delta E}=\frac{2 F}{R T} \exp \left(\frac{2 F \Delta E}{R T}\right)
\end{gathered}
$$

\begin{tabular}{|c|c|c|}
\hline Symbol & Definition & Unit/value \\
\hline$a_{x}$ & Activity of component ' $x$ ' & \\
\hline$B$ & $\begin{array}{l}\text { Number of bins for discretization } \\
\text { of the PSD }\end{array}$ & \\
\hline$C_{\mathrm{O}}$ & Oxygen concentration & $\mathrm{wt} \%$ \\
\hline$C_{\mathrm{O}, \mathrm{s}}$ & Oxygen saturation concentration & wt\% \\
\hline$d_{\mathrm{A}}$ & Interatomic distance & $\mathrm{m}$ \\
\hline$D_{\mathrm{O}}$ & $\begin{array}{l}\text { Diffusion coefficient of oxygen in } \\
\text { LBE }\end{array}$ & $\mathrm{m}^{2} \mathrm{~s}^{-1}$ \\
\hline$E$ & Electric potential difference & $\mathrm{V}$ \\
\hline$F$ & Faraday constant & $96485.34 \mathrm{C} \mathrm{mol}^{-1}$ \\
\hline$\Delta G^{*}$ & $\begin{array}{l}\text { Activation energy for the for- } \\
\text { mation of a critical nucleus }\end{array}$ & $\mathrm{J}$ \\
\hline$\Delta G^{\circ}$ & Activation energy for nucleation & $\mathrm{J}$ \\
\hline$\Delta G_{\mathrm{v}}$ & $\begin{array}{l}\text { Free energy change per unit } \\
\text { volume }\end{array}$ & $\mathrm{J} \mathrm{m}^{-3}$ \\
\hline$G$ & $\begin{array}{l}\text { Change in dissolved oxygen } \\
\text { concentration by growth }\end{array}$ & $\mathrm{kg} \mathrm{s}{ }^{-1}$ \\
\hline$G_{\mathrm{L}}$ & Particle growth rate & $\mathrm{m} \mathrm{s}^{-1}$ \\
\hline$I$ & Driving force for precipitation & $\mathrm{J} \mathrm{mol}^{-1}$ \\
\hline$J$ & Nucleation rate & nuclei $\mathrm{m}^{-3} \mathrm{~s}^{-1}$ \\
\hline$J_{0}$ & $\begin{array}{l}\text { Pre-exponential factor of the } \\
\text { nucleation rate }\end{array}$ & nuclei $\mathrm{m}^{-3} \mathrm{~s}^{-1}$ \\
\hline$K$ & Bin spacing & \\
\hline$k_{\mathrm{B}}$ & Boltzmann constant & $\begin{array}{l}1.3806504 \times \\
10^{-23} \mathrm{~J} \mathrm{~K}^{-1}\end{array}$ \\
\hline$K_{\mathrm{M}_{x} \mathrm{O}_{y}}$ & $\begin{array}{l}\text { Equilibrium constant of } \mathrm{M}_{x} \mathrm{O}_{y} \text { in } \\
\text { LBE }\end{array}$ & \\
\hline$K_{\mathrm{s}}$ & $\begin{array}{l}\text { Sievert constant for oxygen in } \\
\text { LBE }\end{array}$ & \\
\hline
\end{tabular}

Eqn (26) and (29) are used to calculate the uncertainties on the measurement of the oversaturation $S$ due to uncertainties of $\pm 1 \mathrm{~K}$ on temperature and $\pm 1 \mathrm{mV}$ on the potential measurement.

\section{Nomenclature}




\begin{tabular}{|c|c|c|}
\hline$M_{\mathrm{O}}$ & Molar mass of oxygen & $\begin{array}{l}0.015994 \mathrm{~kg} \\
\mathrm{~mol}^{-1}\end{array}$ \\
\hline$N$ & Number of nucleation sites & $\mathrm{m}^{-3}$ \\
\hline$N_{\mathrm{A}}$ & Avogadro constant & $\begin{array}{l}6.02214179 \times \\
10^{23} \mathrm{~mol}^{-1}\end{array}$ \\
\hline$R$ & Particle radius & $\mathrm{m}$ \\
\hline$R$ & Gas constant & $\begin{array}{l}8.3144621 \mathrm{~J} \mathrm{~K}^{-1} \\
\mathrm{~mol}^{-1}\end{array}$ \\
\hline$r_{\mathrm{c}}$ & Critical particle radius & $\mathrm{m}$ \\
\hline$r_{i}$ & Particle radius of bin ' $i$ ' & $\mathrm{m}$ \\
\hline $\mathrm{Re}$ & Reynolds number & \\
\hline$S$ & Oversaturation & \\
\hline $\mathrm{Sc}$ & Schmidt number & \\
\hline Sh & Sherwoord number & \\
\hline$T$ & Temperature & K \\
\hline$V_{\mathrm{LBE}}$ & Molar volume of LBE & $\mathrm{m}^{3} \mathrm{~mol}^{-1}$ \\
\hline$V_{\mathrm{PbO}}$ & Molar volume of $\mathrm{PbO}$ & $\mathrm{m}^{3} \mathrm{~mol}^{-1}$ \\
\hline$Z$ & Zeldovich factor & \\
\hline$\beta$ & CNT frequency factor & $\mathrm{s}^{-1}$ \\
\hline$\sigma$ & Interfacial energy & $\mathrm{J} \mathrm{m}^{-2}$ \\
\hline$\rho_{\mathrm{LBE}}$ & Density of LBE & $\mathrm{kg} \mathrm{m} \mathrm{m}^{-3}$ \\
\hline$\rho_{\mathrm{PbO}}$ & Density of $\mathrm{PbO}$ & $\mathrm{kg} \mathrm{m} \mathrm{m}^{-3}$ \\
\hline$\mu$ & Dynamic viscosity of LBE & $\mathrm{kg} \mathrm{m}^{-1} \mathrm{~s}^{-1}$ \\
\hline$\Gamma$ & Frequency factor $($ see $\beta)$ & $\mathrm{m}^{-2} \mathrm{~s}^{-1}$ \\
\hline
\end{tabular}

\section{Acknowledgements}

K. Gladinez gratefully acknowledges the Association Vinçotte Nuclear (AVN) for supporting his PhD fellowship. The authors acknowledge the Belgian Government for funding the MYRRHA project. We thank A. Verstrepen and S. Huysmans for technical support and assistance during the experimental campaign.

\section{References}

1 M. Frogheri, A. Alemberti and L. Mansani, Fast Reactors and Related Fuel Cycles: Safe Technologies and Sustainable Scenarios (FR13). V. 1. Proceedings of an International Conference, 2015.

2 Y. Wu, Y. Bai, Y. Song, Q. Huang, Z. Zhao and L. Hu, Ann. Nucl. Energy, 2016, 87, 511-516.
3 H. Oigawa, J. Plasma Fusion Res., 2014, 9, 4401113.

4 H. A. Abderrahim, P. Baeten, D. De Bruyn and R. Fernandez, Energy Convers. Manage., 2012, 63, 4-10.

5 C. Fazio, V. Sobolev, A. Aerts, S. Gavrilov, K. Lambrinou, P. Schuurmans, A. Gessi, P. Agostini, A. Ciampichetti and L. Martinelli, et al., Handbook on Lead-bismuth Eutectic Alloy and Lead Properties, Materials Compatibility, Thermalhydraulics and Technologies-2015 Edition, Organisation for economic co-operation and development technical report, 2015.

6 R. Ganesan, T. Gnanasekaran and R. S. Srinivasa, J. Nucl. Mater., 2008, 375, 229-242.

7 A. Kishimoto, A. Wada, T. Michimoto, T. Furukawa, K. Aoto and T. Oishi, Mater. Trans., 2006, 47, 122-128.

8 R. Ganesan, T. Gnanasekaran and R. S. Srinivasa, J. Nucl. Mater., 2006, 349, 133-149.

9 J. Lim, M. Gabriele, A. Marino, K. Gladinez and A. Aerts, J. Electrochem. Soc., 2017, 164, H743-H747.

10 N. Khatcheressian, C. Latgé, X. Joulia, T. Gilardi and X. Meyer, Can. J. Chem. Eng., 2015, 93, 213-224.

11 W. Ostwald, Z. Phys. Chem., 1897, 22, 289-330.

12 R. Becker and W. Döring, Ann. Phys., 1935, 416, 719-752.

13 M. Volmer, et al., 1939.

14 Y. B. Zeldovich, Acta physicochim. URSS, 1943, 18, 1-22.

15 V. Kalikmanov, Nucleation Theory, volume 860 of Lecture Notes in Physics, 2013.

16 N. Rimbert, L. Claudotte, P. Gardin and J. Lehmann, Ind. Eng. Chem. Res., 2014, 53, 8630-8639.

17 G. Pound, Metall. Mater. Trans. A, 1985, 16, 487-502.

18 J. Lehmann, P. Rocabois and H. Gaye, J. Non-Cryst. Solids, 2001, 282, 61-71.

19 H. Vehkamäki, A. Määttänen, A. Lauri, I. Napari and M. Kulmala, Atmos. Chem. Phys., 2007, 7, 309-313.

20 P. M. Armenante and D. J. Kirwan, Chem. Eng. Sci., 1989, 44, 2781-2796.

21 D. R. Uhlmann, J. Non-Cryst. Solids, 1972, 7, 337-348.

22 J. Lim, A. Mariën, K. Rosseel, A. Aerts and J. Van den Bosch, J. Nucl. Mater., 2012, 429, 270-275.

23 J. Lim, G. Manfredi, A. Mariën and J. Van den Bosch, Sens. Actuators, B, 2013, 188, 1048-1054.

24 A. Aerts, S. Gavrilov, G. Manfredi, A. Marino, K. Rosseel and J. Lim, Phys. Chem. Chem. Phys., 2016, 18, 19526-19530.

25 N. Fletcher, J. Chem. Phys., 1958, 29, 572-576. 